NASA Technical Memorandum 103160

\title{
New Directions in InP Solar Cell Research
}

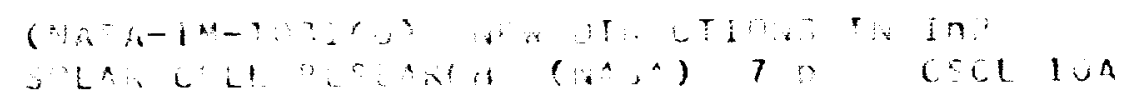

$$
\begin{aligned}
& \text { uncles } \\
& 42 / 3 x \text { 0207+20 }
\end{aligned}
$$

I. Weinberg, C.K. Swartz, and D.J. Brinker

Lewis Research Center

Cleveland, Ohio

Prepared for the

25th Intersociety Energy Conversion Engineering Conference cosponsored by the AIChE, SAE, ACS, AIAA, ASME, and IEEE Reno, Nevada, August 12-17, 1990 

NEW DIRECTIONS IN INP SOLAR CELL RESEARCH

I. Weinberg, C. K. Swartz \& D. J. Brinker

NASA Lewis Research Center

Cleveland, Ohio 44135

ABSTRACT

Recent research efforts, representing new directions in InP solar cell research, are reviewed. These include heteroepitaxial growth on silicon and gallium arsenide substrates, $V$-grooved cells, large area high efficiency cells and surface passivation. Improvements in heteroepltaxial cell efficiency are described together with processing of $19.1 \%, 4 \mathrm{~cm}^{2}$ cells. Recommendations are nade for improvements in processing leading to increased efficiencies.

\section{INTRODUCTION}

Indium phosphide solar cells are known to be more radiation resistant than either gallium arsenide or silicon [1]. Furthermore, AMO efficiencies approaching $22 \%$ are predicted, $19.1 \%$ being the highest efficiency reported to date $[2,3]$. In addition, InP solar cells are currently being used to power a Japanese lunar orbiting satellite [4]. Presiently, a small 4 cell module, on board the LIF'S III satellite, shows no degradation after almost three years in orbit [5]. All of these efforts have been concerned with monolithic $1 / p$ solar cells processed by either organometallic chemical vapor deposition (OMCVD) or diffusion into InP substrates. One disadvantage of these approaches is the high cost of the InP wafers used as starting substrates. Current research efforts, aimed at cost rejuction, include heteroepitaxial growth on cheaper more durable substrates and processing aimed at multiple substrate reuse. In addition to the cost reduction efforts, a research program aimed at increased efficiencies using a $V$-grooved front surface has produced encouraging preliminary results. A third effort, aimed at the processing of large area high efficiency cells has achieved notable success. These efforts, which represent new directions in InP solar cell research, are reviewed in the present paper.

\section{LOW COST APPROACHES}

Fram the viewpoint of reduced cost and increased strength, it would be advantageous to use silicon as a substrate in producing a heteroepitaxial inp solar cell. However, the $7.5 \%$ and $42 \%$ mismatches in lattice constant and expansion coefficient, respectively, introduces difficulties in the use of silicon substrates. In this respect, both germanium and gallium arsenide are preferrable. However, the significant cost reduction arising from the use of silicon and the relative ease of substrate thinning makes use of this substrate most desireable. In any case, intermediate layers are essential in reducing the dislocation densities resulting from the aforementioned mismatches.

Yamaguchi, et al, in their pioneering efforts, used OMCVD to deposit InP directly onto a silicon substrate. This resulted in a cell whose AMO efficiency was 4\% [6]. On the other hand, in a feasibility study, sponsored by NASA Lewis, Spire, using OMCVD, produced InP cells on GaAs substrates (InP/GaAs) and on a silicon substrate with an intermediate GaAs layer (InP/GaAs/Si) [7]. In each case, the InP layer thickness was 4 micrometers. Cell parameters are shown in Table I, together with values obtained from the theoretical predictions of Yamaguchi, et al [8]. Parenthetically, it is noted that all measurements reported in this paper were performed at NASA Lewis, at $25^{\circ} \mathrm{C}$, using an InP flight calibrated standard cell and an AMO solar intensity of $137.2 \mathrm{~mW} \mathrm{~cm}-2$. The low efficiencies are due to the high density of dislocations which in turn result in extremely small values of diffusion lengths [8]. The lower efficiency of the InP/GaAs/Si cell is attributed to doping of the GaAs by $\mathrm{Si}$ [7]. Since deposition of the GaAs layer occurs at $1000{ }^{\circ} \mathrm{C}$, silicon, which is an n-dopant in InP, diffuses into the GaAs layer, creating a reverse diode. To circumvent this effect, the GaAs layer was appropriately 
shorted out [7]. This, however, creates a high resistance path for holes arriving at the back surface, leading to increased series resistance. This is illustrated in figure 1 where the effects of series resistance are clearly evident in the I-V curve of the InP/GaAs/Si cell. The radiation resistance of the heteroepitaxial cells is shown to be significantiy higher than that of the usual homoepitaxial InP cells after $10 \mathrm{MeV}$ electron irradiation [9]. However, this is attributable to the high dislocation densities wich dominate the present heteroepltaxial cell performance. In fact, the present cells have dislocation densities in the $10^{8} \mathrm{~cm}^{-2}$ range. Hence a reduction by several orders of magnitude is required to reach efficiencies over $18 \%$. obviously additional transition layers are needed to reduce the effects of mismatch between cell and substrate. This approach has been pursued by Wanlass at SERI (10). The inftial result, using a GaAs substrate, was a heteroepitaxial InP cell wose AMO efficiency was 13.7\% [10]. A major difference between this latter cell and both of the Spire heteroepitaxial cells is the use of a GaxInj-xAs transition layer. In fact this latter semiconductor with $x=0.47$ is lattice matched to InP, resulting in an order of magnitude decrease in dislocation density. This pre1 iminary result is highly encouraging and cell performance should improve with additional effort. Although a GaAs substrate was used, future efforts will be directed towards use of the more desireable silicon substrate. There still remains the problem of autodoping by the silicon. However, it is felt that appropriately heavy doping of the $p^{+}$buffer layer. next to the silicon substrate, should overcome this difficulty.

The preceding approaches use OMCVD to deposit the cell structure and transition layers on the relatively thick substrate. In another approach, liquid phase epitaxy (LPE) is used to deposit the thin, single crystal, films on a silicon substrate [11]. The potential of this technique has been demonstrated by fabricating LED's from InP films grown on silicon with transition layers grading from GaP to In Gaj-xp. The future near term goals of this research include the processing of solar cells using other types of transition layers. However, at the time of this writing, no cell fabrication results have been reported.

Another approach towards cost reduction makes use of processes wich allow for multiple substrate reuse. In this regard, the CLEFT [12] and chemical ifft-off techniques (13) are designed to produce thin cells which are lifted off reusabie substrates. The substrates can then be reused to produce additional cells. The CLEFT process has produced GaAs cells whose efficlency, measured at NASA Lewis, was $20.5 \%$. The chem ilft off process has also been used to produce device quality GaAs films. In the expectation that the success with GaAs could be transferred to InP, the Lewis Research Center has initiated a program, at the Kopin Corporation, in which InP cells are to be produced by both processes. To date, InP f1lms have been successfully iffted off from InP substrates using the chemical 1 ift-off process. In this latter case, a thin pseudomorphic Alas release layer was used with HF as the releasing agent. The CLEFT process has been demonstrated for an InP layer grown on an intermediate GaAs layer which was laterally overgrown on a GaAs substrate. The next step includes demonstration of lateral overgrowth of InP on an InP substrate with subsequent cleavage of the InP film. After successful demonstration of film separation, InP solar cells will be produced by both 11ft-off processes. Although in their enbryo stages, it is expected that both processes will eventually result in lower cost, lightweight and highly efficient InP solar cells.

\section{Y-GROOVED INP SOLAR CELLS}

Preliminary research on $V$-grooved InP solar cells has been conducted at NASA Lewis [14]. The cell geometry is shown schematically in figure 2. The grooves are formed by anisotropic etching, the etch rate being dependent on the orientation of the etched face $[14,15$, 16]. Before etching, the cell surface is in the $(100)$ direction. After etching, the slanted surface is in the (111) direction. The enitter of the $n^{+} p$ InP cell was formed by closed ampoule diffusion of sulphur using In $\mathrm{S}_{3}$ as a diffusion source [14].

The main advantage of the $V$-grooved cell is lower total surface reflection. A disadvantage is the increased dark current due to the increased junction area. This latter effect leads to decreased cell voltage. Preliminary calculations indicate an expected increase of $10 \%$ in Isc and a $14 \mathrm{mV}$ decrease in Voc. Al though not spectacular, the initial results for a few unoptimized, low efficiency cells, are encouraging. As shown in figure 3 , the quantum efficiency of the $V$-grooved cells are greater than that of the planar InP cell. In comparing three $V$-grooved cells to two planar cells the increase in Isc was $8 \%$ while the decrease in Voc was 37 millivolts. The much greater than expected reduction in Voc may be due to poor surface quality of the grooved cells, inadequate diffusion into the (111) face and striations and other imperfections in the grooved surface. Since the $V$-grooved cell processing is still in the experimental stage, additional effort is needed to effect improvements. In addition, the antireflection coating needs to be optimized before any meaningfui compariston in cell efficiencies can be made. Eventually, the cells will be processed by OMCVD to attain the highest efficiencies. 


\section{LARGER AREA-HIGH EFFICIINCY CELLS}

In previous years, the highest efficiency InP solar cell had an efficiency of $18.8 \%$ [17]. This cell, however, was of relatively small area $\left(0.25 \mathrm{~cm}^{2}\right)$. Since cells of this size are unsuited for practical use, it is essential to show that simflar results can be attained with larger area cells. Most recently, the cell processing has been scaled up to produce $4 \mathrm{~cm}^{2}$ cells whose efficiency was 19.1\% [3]. The AMO parameters for this cell are shown in table II. The previous, smaller area, highest efficiency cell was processed by a combination of OMCVD and ion implantation the latter process being used to form the emitter region of the $n^{+} p^{+}$cell [17]. On the other hand, the $4 \mathrm{~cm}^{2} \mathrm{n}^{+} \mathrm{pp}^{+}$cell was processed entirely by OMCVD [3]. The present high efficiency cell includes a graded emitter structure incorporating a doping of $3 \times 1018$ $\mathrm{cm}^{-3}$ near the maing junctjor and a doping density of $1.5 \times 10^{9} \mathrm{~cm}^{-3}$ at the front surface. In effect, this sreates a front surface field which tends to reduce the flow of emitter minority carriers to the front surface. A surface recombination velocity of $4.5 \times 10^{6} \mathrm{~cm} \mathrm{sec}^{-1}$ was obtained when fitting the measured short wavelength quantum efficiency to calculated results (3). This indicates that surface passivation is necessary to achieve AMO efficlencies over $20 \%$. Hence efforts to achieve the necessary passivation are underway in several laboratories.

Since efforts to achieve largor area, surface passivated, high efficiency Inf cells have only begun to be seriously pursued during the past year, they represent a new direction in Inp solar cell research. In fact, since areas of 8 $\mathrm{cm}^{2}$ are the norm in GaAs cell production, further scale up of the present $4 \mathrm{~cm}^{2}$, high efficiency InP cells is highly desireable.

\section{CONCLUSION}

When compared to previous homcepitaxial planar InP cell research, the efforts in heteroepitaxial growth, CLEFT, chemical ifft off and $\checkmark$-grooved cells represent entirely new directions. Efforts aimed at larger area, surface passivated, high efficiency cells are not entirely new. However, because of their recent emergence, they represent new cirections in InP solar cell research. Although present efficiencies of the heteroepitaxial cells are admittedly low, the recent increase in efficiency from 9 to 13.7\%, for cells based on GaAs substrates, demonstrates the progress which can be affected by the use of more appropriate transition layers. A similar demoristration, using sllicon substrates, has yet to be achieved. However, assuming a solution of the problem presented by silicon autodoping, there appears to be no insurmountable obstacle toward achieving high efficiency cells using silicon as a substrate. InP cells produced by the lift-off processes have yet to be demonstrated. Successful efforts will result in lower cost, lightweight, high efficiency cells, qualities which make them attractive to the spacecraft array designer. The few $V$-grooved cells, produced to date, al though demonstrating higher currents, are of relatively low efficiency. Further development is needed here in the area of cell processing. In fact, it appears necessary to use epitaxial growth rather than diffusion, into Czochralski substrates, to produce the cells. The drive toward larger area cells has shown that sçale up is feasible. In fact, the $19.1 \%, 4 \mathrm{~cm}^{2}$ cells produced to date are slightiy better than the small area cells which demonstrated the previous record high efficiencies. Present efforts, directed at surface passivation, should result in efficiencies greater than $20 \%$.

In sumation, despite the relatively few laboratories engaged in InP solar cell research, the field is dynamic in its exploration of new concepts. Undoubtedly, high efficiencies comparable to GaAs will result from this activity. Furthermore, given sufficient time, one would expect the resultant cells to be low cost, 1 ightweight, and with improved strength to weight ratios. Successful completion of this research effort will result in cells which are prime candidates for extensive use on satellites which experience degrading space radiation environments.

\section{REFERENCES}

[1.] I. Weinberg, C. K. Swartz \& R. E. Hart, Jr., "Radiation and Temperature Effects in GaAs, InP and Si Solar Cells," Proceedings 19 th Photovoltaic Spec. Conf., 548 (1987).

[2.] C. Goradia, W. Thesling \& I. Weinberg "Key Factors Limiting the Open Circuit Voltage of $n^{+} p^{+}$InP Solar Cells," To Be Published in Proceedings $21 \mathrm{st}$ Photovoltaic Specialists Conf., Kisstmee FL, May 21-25, (1990).

[3.] C. J. Keavney, V. E. Haven \& S. M. Vernon, "Surface Recombination and High Effi-ciency in InP Solar Cells," Proceedings 2nd Int'1. Conf. on InP and Related Materials," To Be Published, (IEEE-LEOS, 1990).

[4.] T. Takamoto, H. Okazaki, H. Takamura, M. Ohmorl, M. Ura and M. Yamaguchi, "Radiation Effects on $n^{+} p$ Homojunction InP Solar Cells," Ibid, To Be Published. 
[5.] 0. J. Brinker, "Recent Results From the InP homojunction Cell Module on the LIPS III Spacecraft," To Be Published in Proceedings 20th IEEE Photovoltaic Specialists Conf., Kissimmee, FL, May 21-25, (1990).

[6.] M. Yamaguchi, "Present Status and Future Prospects of InP Solar Cells," Proceedings 20th IEEE Photovol tafc Specialists Conf., 880 (1988).

[7.]. C. J. Keavney, S. M. Vernon, Y. E. Haven, S. J. Wojtczuk \& M. M. Al-Jass im, "Fabrication of $n+/ p$ Inp Solar Cells on Silicon Substrates," Appl. Phys. Lett., 54, 1139 (1989).

[8.] M Yamaguchi, A. Yamamoto, N. Uchida \& C. Uemura, "A new Approach for Thin Film Inp Solar Cells," Solar Cells 19, 85 (1986-1887).

[9.] I. Weinberg, C. K. Swartz, D. J. Brinker \& D. M. Wilt, "Heteroepitaxialy Grown InP Solar Cells," Proceedings 2nd Int' 1 Conf. on InP and Related Materials," To Be Published (IEEELEOS, 1990).

[10.] M. W. Wanl ass, T. A. Gessert, G. S. Horner, J. S. Ward, T. J. Coutts, G. F. Virshup \& M. $i$ : Rostow, "Recent Advances in Epitaxial InP Based Solar Cells," Ibid.

[11.] S. R. Collins \& A. M. Barnett, "Selective Liquid Phase Epitaxial Growth of InP on silicon," Ibid.
[12.] J. C. C. Fan, C. O. Bozler \& R. W. Mclelland, "Thin Film GaAs Solar Cells," Proceedings 15th IEEE Photovoltaic Specialists Conf., 666 (1981).

[13.] E. Yablanovitch, T. Gmitter, J. P. Harbison and R. H. Batt, "Extreme Selectivity in the Lift-off of Epitaxial GaAs," Appl. Phys. Lett. 51, 2222 (1987).

[14.] S. Bailey, N. Fatemi, G. A. Landis, D. J. Brinker, M. Faur and M. Faur, "Application of $V$-groove Technology to InP Solar Cells," Proceedings 2nd Int'l Conf. on InP \& Related Materials, To Be Published, (IEEE-LEOS, 1990).

[15.] C. R. Baraona and H. W. Brandhorst, "V-grooved Silicon Solar Cells," Proceedings 10th IEEE Photovoltaic Specialists Conf. 44 (1975).

[16.] C. V. Keavney \& H. I. Smith, "A 3.8 Micrometer Period Sawtooth Grating in InP by Anisotropic Etching," J. Electrochem. Soc., $131,452(1984)$.

[17.] C. J. Keavney \& M. B. Spitzer, "Indium Phosphide Solar Cells Made by Ion Implantation," App1. Phys. Lett., 52, 1439 (1988).

\begin{tabular}{|c|c|c|c|c|}
\hline \multirow[t]{2}{*}{ Cell } & $\underline{\mathrm{JSC}}$ & Voc & $\underline{F F}$ & Efficiency \\
\hline & $\mathrm{ma} / \mathrm{cm}^{2}$ & $\mathrm{mv}$ & $q$ & $q$ \\
\hline $\operatorname{InP} / \mathrm{GaAs}^{\mathrm{a}}$ & $26.6 \pm .7$ & $667 \pm 4$ & $69 \pm 1$ & $8.9 \pm .1$ \\
\hline $\operatorname{InP} / G a A s / S i^{a}$ & $25.8 \pm .3$ & $642 \pm 4$ & $57.7 \pm 1$ & $6.95 \pm .1$ \\
\hline predictedb & 29.6 & 600 & 77 & 9.9 \\
\hline \multicolumn{5}{|c|}{$\begin{array}{l}\text { A Average } 8 \mathrm{ce} 11 \mathrm{~s} \\
b_{N_{D}}=3 \times 10^{8} / \mathrm{cm}^{2}, p=3 \times 1016 \mathrm{~cm}^{-3}, 5 \% \text { front contact coverage }\end{array}$} \\
\hline
\end{tabular}

\begin{tabular}{|c|c|c|c|}
\hline \multicolumn{4}{|c|}{$\begin{array}{l}\text { Table II Parameters of High Efficiency } \\
\qquad 4 \mathrm{~cm}^{2} \operatorname{InP} \text { Cell }\end{array}$} \\
\hline$\underline{\text { Jsc }}$ & Voc & $\underline{F F}$ & Efficiency \\
\hline $\mathrm{ma} / \mathrm{cm}^{2}$ & $\mathrm{mV}$ & \% & $\%$ \\
\hline 36.34 & 876 & 82.4 & 19.1 \\
\hline
\end{tabular}




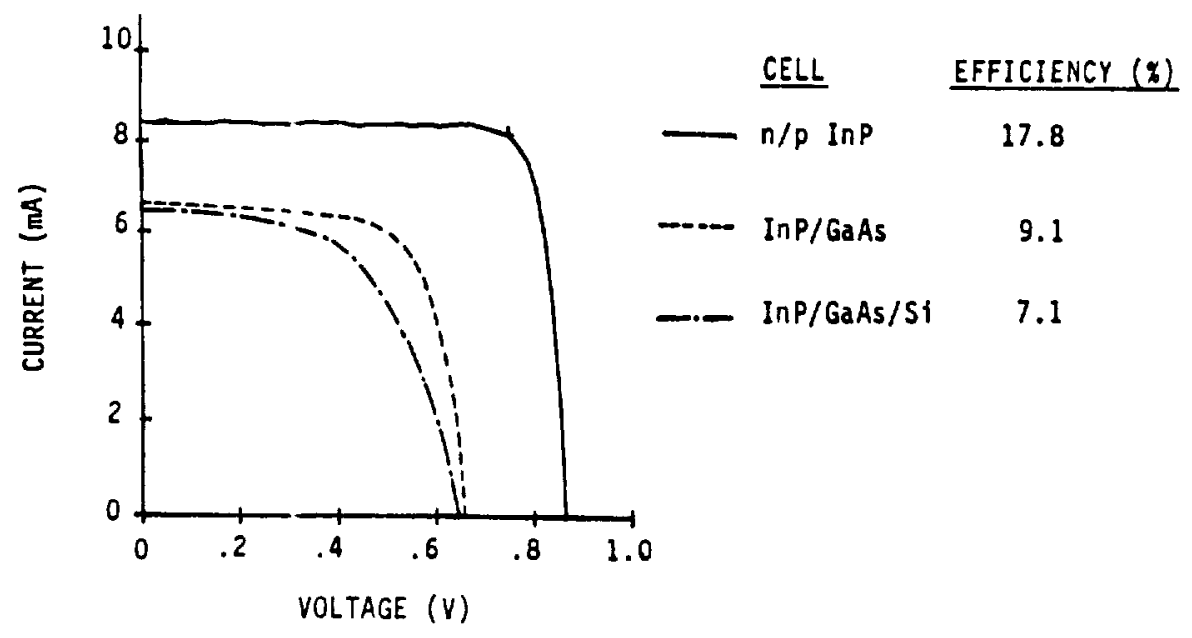

Fig. 1. I- $V$ curves of $n / p$ homojunction and present heteroepitaxial cells

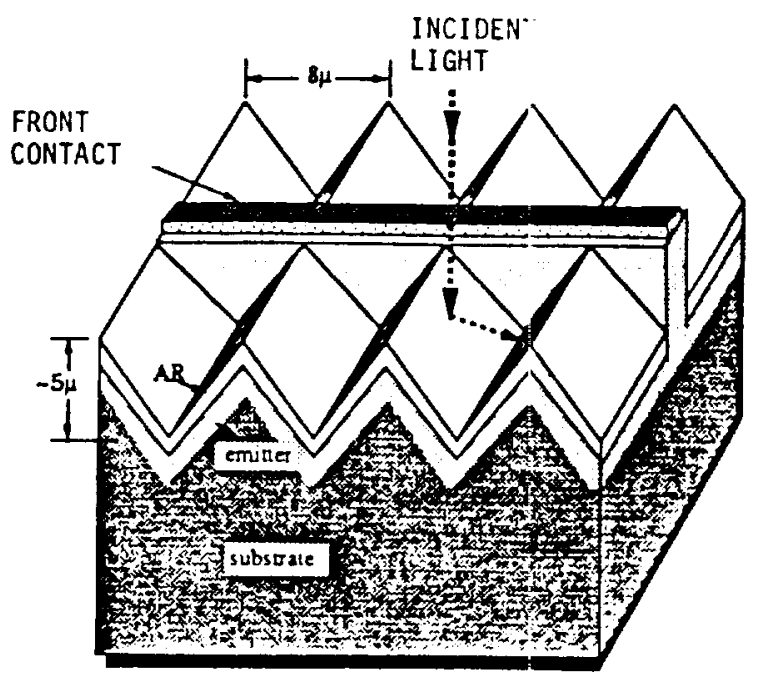

Fig. 2. Schematic of $V$-grocred cell

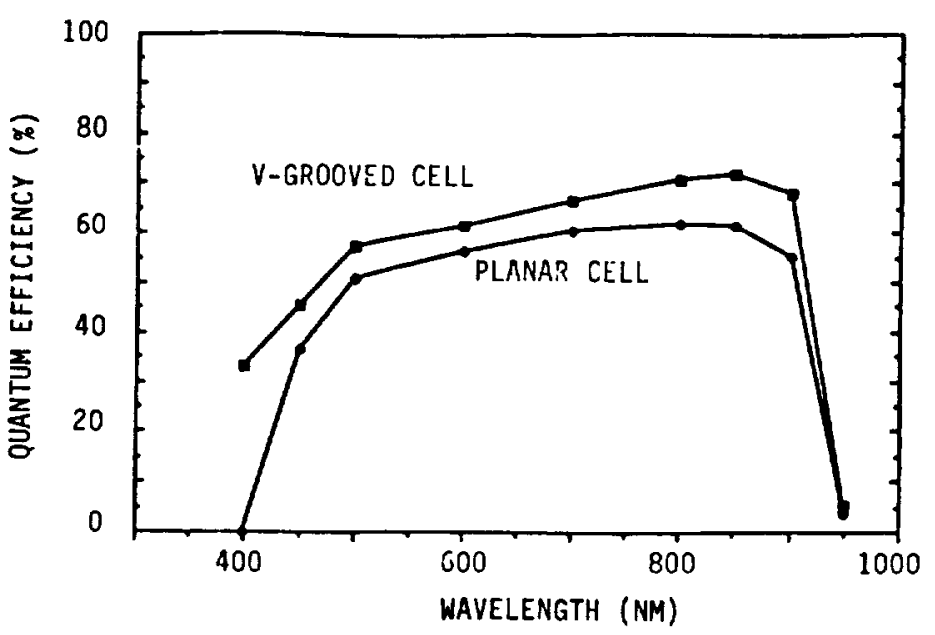

Fig. 3. Quantum efficiency-V-grooved and planar cell. (no antireflection coating) 


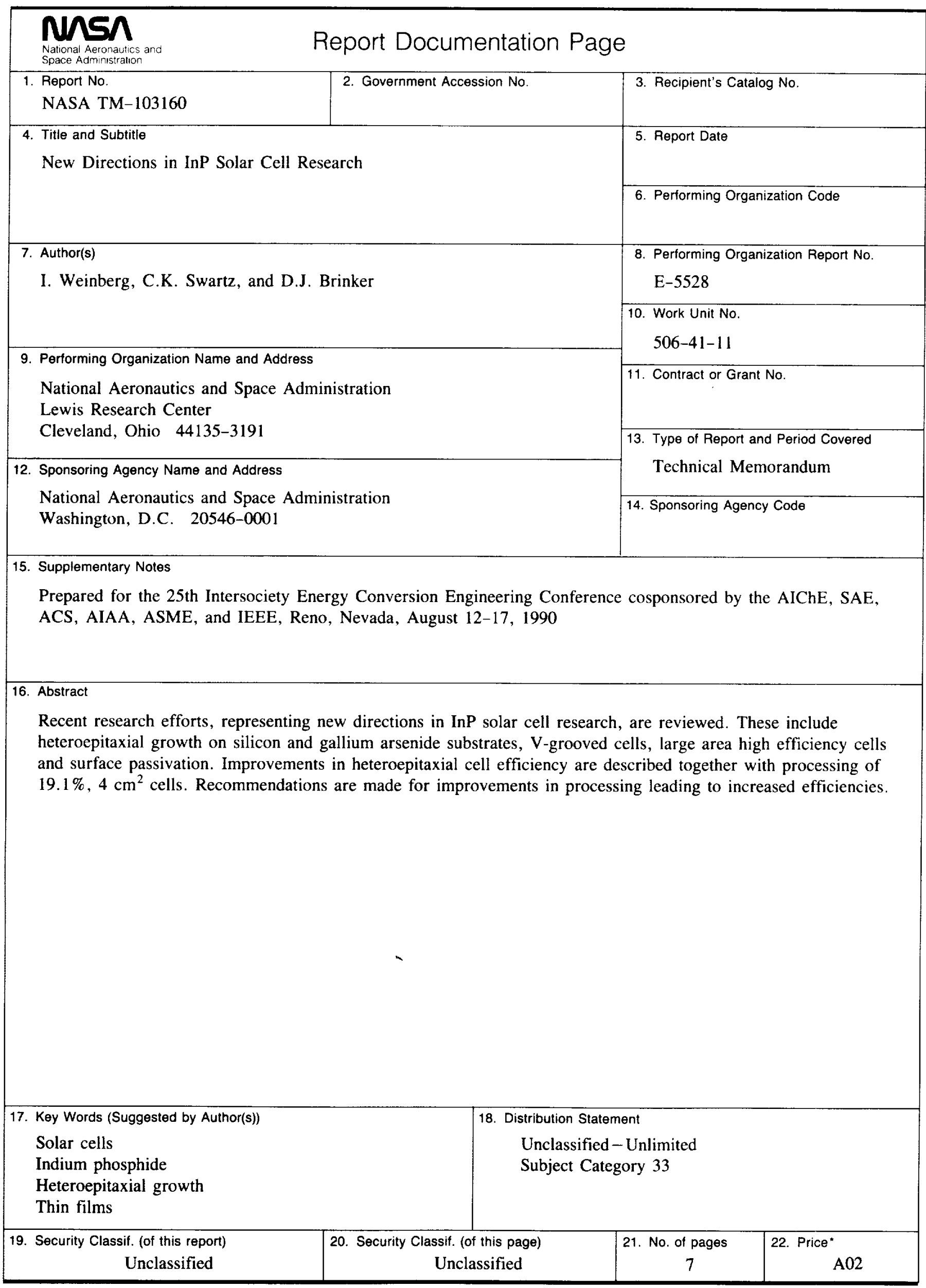

